\title{
Positively charged cholesterol-recombinant human gelatins foster the cellular uptake of proteins and murine immune reactions
}

This article was published in the following Dove Press journal:

International Journal of Nanomedicine

10 October 2012

Number of times this article has been viewed

\author{
Pallavi A Kadengodlu' ${ }^{1,3}$ \\ Takehisa Hebishima ${ }^{2}$ \\ Shin-Nosuke Takeshima ${ }^{2}$ \\ Mika Ito' \\ Mingzhe Liu' \\ Hiroshi Abe' \\ Yoko Aida ${ }^{2}$ \\ Toshiro Aigaki ${ }^{3}$ \\ Yoshihiro Ito 1,3 \\ 'Nano Medical Engineering \\ Laboratory, ${ }^{2}$ Viral Infectious Diseases \\ Unit, RIKEN Advance Science \\ Institute, Wako, Saitama, Japan; \\ ${ }^{3}$ Graduate School of Biological \\ Science, Tokyo Metropolitan \\ University, Tokyo, Japan
}

Correspondence: Yoshihiro Ito

Nano Medical Engineering Laboratory,

RIKEN Advance Science Institute,

2-I Hirosawa, Wako,

Saitama 35I-0I98, Japan

Tel +8I 484675809

Fax +8I 484679300

Email y-ito@riken.jp
Purpose: Recombinant human gelatins with defined molecular weights were modified with cholesterol to make them amphiphilic in nature. We investigated the feasibility of these modified human gelatins acting as a carrier of antigenic proteins for inducing cellular immunity. The aim of this study was to synthesize novel and effective compounds for vaccine delivery in vivo.

Methods: Two types of cholesterol-modified gelatin micelles, anionic cholesterol-modified gelatin (aCMG) and cationic-cholesterol modified gelatin (cCMG), were synthesized using different cholesterol derivatives such as the cholesterol-isocyanate (Ch-I) for aCMG and aminomodified cholesterol for cCMG. One was anionic and the other cationic, and therefore they differed in terms of their zeta potential. The aCMG and cCMG were characterized for their size, zeta potential, and in their ability to form micelles. Cytotoxicity was also evaluated. The modified human gelatins were then investigated as a carrier of antigenic proteins for inducing cellular immunity both in vitro in DC 2.4 cells, a murine dendritic cell line, as well as in vivo. The mechanism of entry of the polymeric micelles into the cells was also evaluated.

Results: It was found that only cCMG successfully complexed with the model antigenic protein, fluorescein-isothiocyanate ovalbumin (OVA) and efficiently delivered and processed proteins in DC 2.4 cells. It was hypothesized that cCMG enter the cells predominantly by a caveolae-mediated pathway that required tyrosine kinase receptors on the cell surface. Animal testing using mice showed that the cationic cholesterol-modified gelatin complexed with OVA produced significantly high antibody titers against OVA: 2580-fold higher than in mice immunized with free OVA.

Conclusion: Conclusively, cCMG has shown to be very effective in stimulating an immune response due to its high efficiency, stability, and negligible cytotoxicity.

Keywords: recombinant human gelatin, cholesterol, micelle, protein delivery, caveolae pathway, receptor-mediated endocytosis

\section{Introduction}

Vaccine administration has always been an attractive option in the treatment of a broad range of infectious diseases or even cancers by inducing effective immune responses. Delivering antigenic proteins to dendritic cells (DCs), which play a pivotal role in immunology, helps in activating antigen-specific cytotoxic $\mathrm{T}$ lymphocytes by processing antigenic proteins to the peptides that are important in achieving targetspecific immunity by eliminating infected cells and pathogens directly from the body. ${ }^{1}$ Nanocarriers show great potential in their efficiency to deliver proteins and induce an optimal immune response safely. Several groups have worked on various antigendelivery carriers. ${ }^{2-4}$ Polymer-derived nanoparticles are used extensively for vaccine delivery and have been approved for human use. ${ }^{5}$ 
Although many synthetic polymers are being used for biomedical applications, natural polymers have always remained an attractive choice because they have good biocompatibility, low toxicity, and can be fabricated readily by simple chemistry. Among the strategies used to synthesize polymeric nanocarriers by natural polymers, researchers have introduced hydrophobic segments such as cholesterol, ${ }^{6}$ tocopherol, ${ }^{7}$ and deoxycholic acid, ${ }^{8}$ thus making the polymers amphiphilic in nature. Such amphiphilic polymers have the ability to self-aggregate and hence act as efficient carriers. Thus, it is possible to design nanocarriers made of only natural materials by choosing natural hydrophobic segments.

Among the many natural polymers, gelatin represents a good raw material as a delivery system because of its affinity to cells. ${ }^{9-12}$ However, there are some drawbacks. Cross-linking with chemical compounds that are usually toxic is needed typically to prepare a gelatin nanocarrier. ${ }^{13}$ Transmittable diseases or allergic reactions such as anaphylaxis have been reported from gelatins originating from animal sources. ${ }^{14,15}$ Lastly, nanoparticles prepared from conventional gelatins pose a significant challenge to analytical characterization because of their heterogeneous nature, as they are made up of a mixture of differently sized peptides that are heterogeneous in molecular weight (MW). ${ }^{16}$ However, of the many nanoparticles developed, only a few possess properties that allow them to be used further in vivo to test their therapeutic abilities.

In this study, we used recombinant human gelatin (rhG) derived from human collagen. This overcomes the above limitations as it is homogeneous in MW, nontoxic, and is being considered as an alternative to conventional gelatin extracted from bovine or porcine sources. ${ }^{17,18}$ We report the synthesis of two types of rhG derivatives by using two kinds of cholesterol derivatives. They have the ability to form micelles but differ in terms of their zeta $(\zeta)$-potential. They are referred to here as anionic cholesterol-modified gelatin $(\mathrm{aCMG})$ and cationic cholesterol-modified gelatin (cCMG).

\section{Material and methods Materials}

Recombinant human gelatin (MW $89.8 \mathrm{kDa}$ ) was purchased from Neosilk (Hiroshima, Japan). 1-Ethyl-3-(3dimethylaminopropyl)carbodiimide hydrochloride (EDC) was obtained from Dojindo Laboratories (Kumamoto, Japan). Ethylenediamine was purchased from Tokyo Chemical Industry Co, Limited (Tokyo, Japan) and ovalbumin (OVA), fluorescein isothiocyanate-labeled OVA (FITC-OVA), chlorpromazine, nystatin and cytochalasin D were obtained from Sigma-Aldrich (St Louis, MO). 4',6-Diamidino-2phenylindole (DAPI) and Vectashield mounting medium were purchased from Vector Laboratories (Burlingame, CA). LysoTracker ${ }^{\mathrm{TM}}$ Red DND-99 was obtained from Invitrogen (Carlsbad, CA). OVA-DQ ${ }^{\mathrm{TM}}$ was purchased from Molecular Probes (Eugene, OR). Cholesterol, hexamethylene diisocyanate, toluene (dry), pyridine (dry), triethylamine (TEA), hexane, dimethylsulfoxide (DMSO) (dehydrated), dichloromethane, 4\% paraformaldehyde in phosphatebuffered saline (PBS), pyrene, and genistein were obtained from Wako Pure Chemical Industries, Ltd (Osaka, Japan).

\section{Cell culture}

The immature dendritic cell line DC 2.4 was kindly provided by Dr Kenji Kono (Osaka Prefecture University, Osaka, Japan) with the permission of Dr KL Rock (Harvard Medical School, Boston, MA). The cells were cultured at $37^{\circ} \mathrm{C}$ in RPMI-1640 medium with L-glutamine (Gibco BRL, Invitrogen) and supplemented with $10 \%$ fetal bovine serum (FBS), $100 \mu \mathrm{M}$ nonessential amino acids, $50 \mu \mathrm{M}$ 2-mercaptoethanol, and antibiotics.

\section{Mice}

Six- to 10-week-old female C57BL/6NCrSlc mice (Japan SLC Inc, Shizuoka, Japan) were maintained at the animal facilities of RIKEN Brain Science Institute (Saitama, Japan) according to the guidelines of the institution. The mice were kept in an air-conditioned room and fed standard laboratory food and water ad libitum. All experiments were approved by the RIKEN Animal Experiments Committee.

\section{Synthesis of cholesterol derivatives}

Cholesteryl N-6-(isocyanatohexyl carbamate) or cholesterol isocyanate (Ch-I) was synthesized as reported previously. ${ }^{6}$ Briefly, cholesterol (7.80 g, $20.12 \mathrm{mmol})$ was reacted with 1,6-hexyldiisocyanate $(64 \mathrm{~mL}, 0.39 \mathrm{~mol})$ in $200 \mathrm{~mL}$ of dry toluene containing $15 \mathrm{~mL}$ of pyridine at $80^{\circ} \mathrm{C}$ for 48 hours. The reaction was monitored using thin-layer chromatography (TLC). After the removal of solvent in vacuo, $500 \mathrm{~mL}$ of hexane was added to the residue and kept overnight at $-20^{\circ} \mathrm{C}$. The precipitates thus obtained were then separated and dried in vacuo to give a yield of $3.88 \mathrm{~g}(49.74 \%)$. Proton nuclear magnetic resonance $\left({ }^{1} \mathrm{H} \mathrm{NMR} ; 400 \mathrm{MHz}, \mathrm{CDCl}_{3}, 25^{\circ} \mathrm{C}\right)$ : $\delta=0.60\left(\mathrm{~s}, 3 \mathrm{H}\right.$, cholesterol-18 $\left.\mathrm{H}_{3}\right), 0.78-2.30(\mathrm{~m}, 40 \mathrm{H}$, cholesterol), 1.30-1.56 (m, 8H), $3.09(\mathrm{~m}, 2 \mathrm{H}), 3.22\left(\mathrm{t},{ }^{3} \mathrm{~J}\right.$ $(\mathrm{H}, \mathrm{H})=6.8 \mathrm{~Hz}, 2 \mathrm{H}), 4.42-4.51(\mathrm{~b}, 1 \mathrm{H}$, cholesterol), and $5.30(\mathrm{~m}, 1 \mathrm{H}$, cholesterol). 
Cholesteryl N-6-(3-(2-aminoethyl)ureido)hexyl carbamate or amino-modified cholesterol (Ch-A) was synthesized as follows. A solution of Ch-I (200 mg, $0.360 \mathrm{mmol})$ in dichloromethane $(10 \mathrm{~mL})$ synthesized in the previous step was added dropwise to a vigorously stirred solution of ethylenediamine $(0.481 \mathrm{~mL}, 7.2 \mathrm{mmol})$ in an excess of dichloromethane $(25 \mathrm{~mL})$ at room temperature $(\mathrm{RT})$. The disappearance of cholesteryl N-(6-isocyanatohexyl)carbamate was monitored using TLC. The solvent was removed in vacuo and the compound was extracted using a 1:1 chloroform-to-water ratio giving a yield of $144.57 \mathrm{mg}(72.2 \%) .{ }^{1} \mathrm{H} \mathrm{NMR}\left(400 \mathrm{MHz},\left[\mathrm{D}_{6}\right]\right.$ DMSO, $\left.25^{\circ} \mathrm{C}, \mathrm{TMS}\right): \delta=0.65$ (s, 3H, cholesterol), $0.84-2.33$ (m, 40H, cholesterol), 1.41-1.55 (m, 8H), 1.22-1.23 (m, 2H), 2.92-3.00 (m, 8H), 4.27-4.32 (m, 1H, cholesterol), 5.34 (b, 1H, cholesterol), 5.80-5.85 (m, 2H), 7.03 (m, 1H). HRESI-MS: $m / z$ calculated for $\left(\mathrm{C}_{37} \mathrm{H}_{66} \mathrm{~N}_{4} \mathrm{O}_{3}\right)\left([\mathrm{M}-\mathrm{H}]^{-}\right) 614.5134$; found, 614.5208 .

\section{Syntheses of cholesterol-modified gelatins}

aCMG was synthesized from $\mathrm{Ch}-\mathrm{I}$ and $\mathrm{rhG}$ as follows. rhG (100 mg, $0.0273 \mathrm{mmol}$, corresponding to the lysine moieties and N-terminal) was dissolved in DMSO (15 mL) and reacted with Ch-I (7.56 mg, $0.0136 \mathrm{mmol})$ in DMSO $(5 \mathrm{~mL})$ containing TEA $(1 \mathrm{~mL}, 7.16 \mathrm{mmol})$ at $50^{\circ} \mathrm{C}$. The reaction was monitored using TLC until the disappearance of Ch-I was confirmed (developed using chloroform). It was then dialyzed against distilled water and freeze-dried to give a yield of $66 \mathrm{mg}(66 \%)$.

cCMG was synthesized using an EDC-coupling method wherein Ch-A (23.22 mg, $0.0378 \mathrm{mmol}$ ) was reacted with rhG (100 mg, $0.0756 \mathrm{mmol}$, corresponding to the Asp and Glu moieties and the C-terminal) in $15 \mathrm{~mL} \mathrm{DMSO}$ (Ch-A and rhG were dissolved separately in DMSO). To this mixture, an EDC- $\mathrm{HCl}$ solution (144.89 mg, $0.756 \mathrm{mmol}$ ), prepared freshly in $8 \mathrm{~mL}$ of DMSO, was added to the rhG and Ch-A mixture to obtain a 10-fold excess in the amounts of Asp and Glu. It was then allowed to react at room temperature overnight and dialyzed against distilled water to remove solvent and excess reagents including any byproducts such as isourea formed during the reaction, and lyophilized. Yield was $56 \mathrm{mg}(56 \%)$.

\section{Matrix-assisted laser desorption/ ionization time-of-flight mass spectrometry (MALDI-TOF/MS)}

The conjugation of cholesterol with rhG was confirmed by MALDI-TOF/MS. All mass measurements were performed using a microflex MALDI-TOF mass spectrometer (Bruker Daltonics Inc, Billerica, MA).

\section{Micelle formation and determination of critical micelle concentration (CMC)}

Polymeric micelles were prepared by hydration of aCMG or cCMG in distilled water or PBS; they dispersed easily to give a uniform suspension on vortexing. The CMC values were estimated by fluorescence spectroscopy using pyrene as the fluorescence probe as described previously. ${ }^{19}$ Briefly, the concentration of pyrene was kept constant at $0.6 \mu \mathrm{M}$ while the concentrations of the polymeric micelles were varied from $1 \times 10^{-7}$ to $1 \mathrm{mg} / \mathrm{mL}$. The fluorescence spectra were recorded using a fluorescence spectrophotometer (JASCO FP-6500; Jasco Corp, Tokyo, Japan) with an excitation wavelength of $320 \mathrm{~nm}$. Fluorescent light emissions were monitored at 372 and $383 \mathrm{~nm}$. The CMC was estimated as the cross-point when extrapolating the intensity ratio $\mathrm{I}_{372} / \mathrm{I}_{383}$ at low- and high-concentration regions.

\section{Scanning electron microscopy (SEM)}

The morphology of the polymeric micelles was analyzed by SEM (JEM-6330; JEOL Instruments, Tokyo, Japan). SEM measurements were carried out at an accelerating voltage of $15 \mathrm{kV}$. The samples were prepared by dropping $10 \mu \mathrm{L}$ of the micelle solution $(1 \mathrm{mg} / \mathrm{mL})$ onto a carbon seal attached to a metallic specimen holder, followed by air-drying for a day. The samples were then sputter-coated with gold before observation.

\section{Cytotoxicity assay}

The cytotoxicity of the polymeric micelles was determined using a WST cell viability assay. DC 2.4 cells were seeded in a 96-well plate at a concentration of $2 \times 10^{4}$ cells/well and cultured in complete medium for 24 hours at $37^{\circ} \mathrm{C}$ under $5 \%$ humidified $\mathrm{CO}_{2}$. The culture medium was then replaced with fresh complete medium containing aCMG, cCMG, or rhG at predetermined concentrations and incubated under the same conditions for 24 hours. Then the cells were washed twice with PBS, and complete medium was added to the cells. Aliquots of $10 \mu \mathrm{L}$ of cell counting kit-8 solution (CCK-8; Dojindo Laboratories) were then added to the medium and shaken for 30 seconds to mix the solution thoroughly and then incubated at $37^{\circ} \mathrm{C}$ for 30 minutes. The absorbance of each well was measured using a microplate reader (Model-680; Bio-Rad, Hercules, CA) at $450 \mathrm{~nm}$. The percentage of cell viability was calculated from the absorbance values. 


\section{Preparation of polymeric micelles and FITC-OVA complexes}

To prepare the polymeric micelle and protein complexes, aqueous solutions of FITC-OVA and polymeric micelles were mixed, vortexed gently, and incubated at RT for 30 minutes. Native rhG served as a control because it does not form a complex with OVA.

\section{Size and zeta $(\zeta)$-potential measurements}

The mean hydrodynamic size and polydispersity index of rhG, aCMG, and cCMG were determined by dynamic light scattering (DLS) using a Zetasizer Nano ZS (Malvern Instruments Ltd, Malvern, UK). Measurements were carried out at $25^{\circ} \mathrm{C}$. The $\zeta$-potential (in $\mathrm{mV}$ ) was also determined using the Zetasizer Nano ZS. The size and $\zeta$-potential are reported as the mean \pm standard deviation (SD) of 14 subruns.

\section{Cellular uptake efficiency of polymeric micelles measured by flow cytometry}

Dual-color fluorescence-activated cell sorting (FACS) analysis was performed to quantify the uptake of FITC-OVA by the polymeric micelles in DC 2.4 cells. The cells were seeded at a concentration of $1 \times 10^{6}$, cultured in RPMI1640 medium supplemented with $10 \%$ FBS and incubated with the samples for 1 hour at $4{ }^{\circ} \mathrm{C}$ and $37^{\circ} \mathrm{C}$. The cells were then washed with PBS and collected in PBS containing $0.25 \mu \mathrm{g} / \mathrm{mL}$ of 7-amino-actinomycin D (7-AAD) to stain the dead cells. Uptake of FITC-OVA was analyzed using a BD FACSCalibur (Becton-Dickinson, Tokyo, Japan). Results are expressed as the mean fluorescence intensity. Specific uptake was assessed by subtracting the mean fluorescence intensity of the cells incubated at $4^{\circ} \mathrm{C}$ from that recorded at $37^{\circ} \mathrm{C}$.

\section{Fluorescence microscopy}

For fluorescence microscopy, the DC 2.4 cells were seeded at a concentration of $1 \times 10^{5}$ cells and cultured for 24 hours in a 35-mm glass-bottomed dish containing RPMI-1640 medium supplemented with or without $10 \%$ FBS. For analyzing the cell uptake and subcellular location of FITC-OVA, free FITC-OVA $(15 \mu \mathrm{g})$ or test samples $(80 \mu \mathrm{g})$ complexed with FITC-OVA $(15 \mu \mathrm{g})$ were used. For evaluating antigen processing, cCMG $(80 \mu \mathrm{g})$ complexed with OVA-DQ ${ }^{\mathrm{TM}}$ $(15 \mu \mathrm{g})$ was added gently to the cells and incubated at $37^{\circ} \mathrm{C}$. For cellular uptake and antigen processing, after incubation for the indicated time periods, the cells were washed with PBS and fixed with 4\% paraformaldehyde for 30 minutes at room temperature, after which the nuclei were stained with DAPI. For the subcellular localization of FITC-OVA, after incubation for the required time periods, LysoTracker $\operatorname{Red}^{\mathrm{TM}}(50 \mathrm{nM})$ was added 20 minutes before fixation. The cells were observed using a fluorescence microscope (Carl Zeiss, Göttingen, Germany).

\section{Inhibition studies}

To investigate the mechanism of uptake of the polymeric micelles, DC 2.4 cells were seeded at a concentration of $1 \times 10^{5}$ cells in a $35 \mathrm{~mm}$ culture dish and cultured for 48 hours. The cells were then incubated with four endocytosis inhibitors: nystatin $(25 \mu \mathrm{g} / \mathrm{mL})$, genistein $(300 \mu \mathrm{M})$, chlorpromazine $(15 \mu \mathrm{g} / \mathrm{mL})$ and cytochalasin $\mathrm{D}(10 \mu \mathrm{g} / \mathrm{mL})$ for 1 hour at $37^{\circ} \mathrm{C}$, after which cCMG $(80 \mu \mathrm{g})$ complexed with FITC-OVA $(20 \mu \mathrm{g})$ was added and incubated for 4 hours. Cells incubated with only cCMG complexed with FITC-OVA served as controls. The cells were washed twice with PBS, collected in $1 \%$ bovine serum albumin (BSA) in PBS and the inhibition of FITC-OVA fluorescence was analyzed by flow cytometry (Cytomics ${ }^{\mathrm{TM}}$ FC500; BeckmanCoulter, Miami, FL). Results are expressed as the percentage of fluorescent positive cells.

\section{Immunization and isolation of blood samples and spleens}

To test the efficiency of in vivo antigen delivery, 6-week-old female C57BL $/ 6$ mice were administered with $3.3 \mathrm{mg} / \mathrm{kg}$ of free OVA or polymeric micelles complexed with OVA on days 0 and 14 by intraperitoneal injection. Blood samples were collected from the tail vein on days 7 and 21 for antibody titration. On day 28 , whole blood samples were collected by heart puncture with the animal under deep diethyl ether anesthesia and the spleens were harvested before allowing the mouse to succumb. The spleens were prepared individually as single-cell suspensions in $3 \mathrm{~mL}$ RPMI 1640 supplemented with L-glutamine, $10 \% \mathrm{FBS}$ and $100 \mu \mathrm{g} / \mathrm{mL}$ each of penicillin, streptomycin, and gentamycin. The erythrocytes were removed by suspension in a lysis buffer $\left(0.15 \mathrm{M} \mathrm{NH}_{4} \mathrm{Cl}\right.$, $1 \mathrm{mM} \mathrm{KHCO}_{3}$, and $0.1 \mathrm{mM}$ EDTA-2Na). Splenocytes were washed with complete RPMI medium and live cells counted using a trypan blue exclusion method.

\section{Antibody titration}

Specific antibody titers against OVA were determined by performing an endpoint enzyme-linked immunosorbent assay (ELISA). NUNC MaxiSorp 96-well ELISA plates (Nalge Nunc International, Roskilde, Denmark) were coated with $5 \mu \mathrm{g} / \mathrm{mL}$ of OVA in $0.1 \mathrm{M} \mathrm{NaHCO}_{3}$ (Nacalai Tesque, 
Kyoto, Japan), incubated overnight at $4^{\circ} \mathrm{C}$ and washed with PBS-Tween (PBS-T). The plates were blocked with 3\% BSA in PBS for 1 hour at room temperature and washed with PBS-T. After serial dilution in 1\% BSA in PBS beginning at a 40 -fold dilution, serum samples $(100 \mu \mathrm{L})$ were added into the wells and the plates were incubated for 1 hour at room temperature. The plates were washed with PBS-T and $100 \mu \mathrm{L}$ of peroxidase-conjugated goat anti-mouse IgG (heavy chain- and light chain-specific, diluted 32000-fold in 1\% BSA in PBS; Jackson ImmunoResearch Laboratories Inc, West Grove, WA) was added to each well. The plates were incubated for 1 hour at room temperature and then washed with PBS-T. Finally, colorimetric signals were generated using 1 Step Ultra TMB-ELISA solution (Pierce Biotechnology Inc, Rockford, IL). The reaction was stopped with $1 \mathrm{~N} \mathrm{H}_{2} \mathrm{SO}_{4}$ after 15 minutes and the absorbance at $450 \mathrm{~nm}$ was measured using a Wallac ARVO counter (Perkin Elmer, Norwalk, CT). The antibody titer was determined as the highest dilution below the cutoff value indicated by the mean optical density value of the background \pm 2 SD.

\section{Statistical analysis}

All the animal experimental data are expressed as the mean \pm SD. Multiple comparisons were performed using oneway analysis of variance (ANOVA) with post hoc analysis followed by Bonferroni's test.

\section{Results and discussion Synthesis of cholesterol derivatives and cholesterol-modified gelatins}

The aCMG and cCMG were synthesized as described in Figures 1 and 2 and confirmed by MALDI-TOF data (Figure 3A). Compositions, MW, and the exact amount of substituted cholesterol in these derivatives are listed in Table 1 . In the case of aCMG, the $\mathrm{NH}_{2}$ groups of 36 lysine residues and one $\mathrm{N}$-terminal in $\mathrm{rhG}$ were targeted for modification by $\mathrm{Ch}$-I, of which 6.7 residues were modified (Table 1). Table 1 also shows the mean hydrodynamic size of formed polymeric micelles $(485 \mathrm{~nm})$ and a net increase in the negative charges resulting in a $\zeta$-potential of $-2 \mathrm{mV}$. It was expected that aCMG would have both hydrophobic cholesterol-modified and hydrophilic-unmodified regions in forming micelles and would attain an overall negative charge as a result of the ionization of the remaining $\mathrm{COOH}$ groups in rhG. On the other hand, in the case of cCMG, $\mathrm{COOH}$ groups of 78 residues of Asp and Glu and one $\mathrm{C}$-terminal were targeted for modification by $\mathrm{Ch}$-A resulting in 9.99 modified residues. The hydrodynamic size of formed polymeric micelles was $350 \mathrm{~nm}$ and there was a net increase in the positive charges resulting in a $+6 \mathrm{mV} \zeta$-potential. It was also expected that cCMG would have both hydrophobic cholesterol-modified and hydrophilic-unmodified regions in forming polymeric micelles and would attain an overall positive charge from ionization of the remaining $\mathrm{NH}_{2}$ groups in $\mathrm{rhG}$.

\section{Characteristics of polymeric micelles}

The CMCs of aCMG and cCMG were estimated to be $1.7 \times 10^{-2} \mathrm{mg} / \mathrm{mL}$ and $2.0 \times 10^{-3} \mathrm{mg} / \mathrm{mL}$, respectively. The native rhG did not have the ability to form micelles and so no CMC was observed (Figure S1). It is known that the hydrophobic nature of cholesterol increases its propensity to form strong hydrophobic interactions..$^{20,21}$ The introduction of cholesterol allows polymeric micelles to be generated and
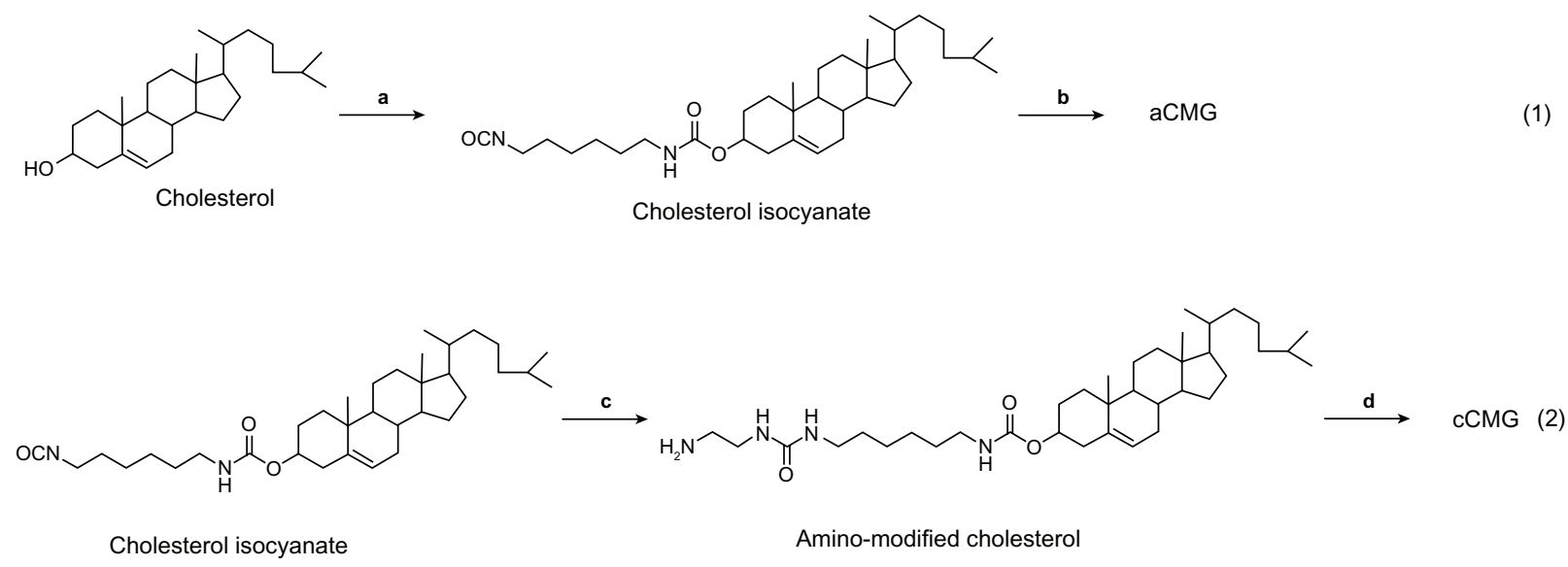

Figure I Synthetic scheme of (I) aCMG - (a) I,6-hexamethylene diisocyanate, toluene, and pyridine at $80^{\circ} \mathrm{C}$; and (b) rhG (targeting $\mathrm{NH}_{2}$ groups of Lys), triethylamine, and $\mathrm{DMSO}$ at $50^{\circ} \mathrm{C}$, and (2) CCMG - (c) ethylenediamine and dichloromethane at RT; and (d) rhG (targeting COOH groups of Asp and Glu), using the EDC coupling agent, DMSO at RT. Abbreviations: aCMG, anionic cholesterol-modified gelatin; cCMG, cationic cholesterol-modified gelatin; DMSO, dimethyl sulfoxide; EDC, I-ethyl-3-(3-dimethylaminopropyl) carbodiimide hydrochloride; rhG, recombinant human gelatin; RT, room temperature. 


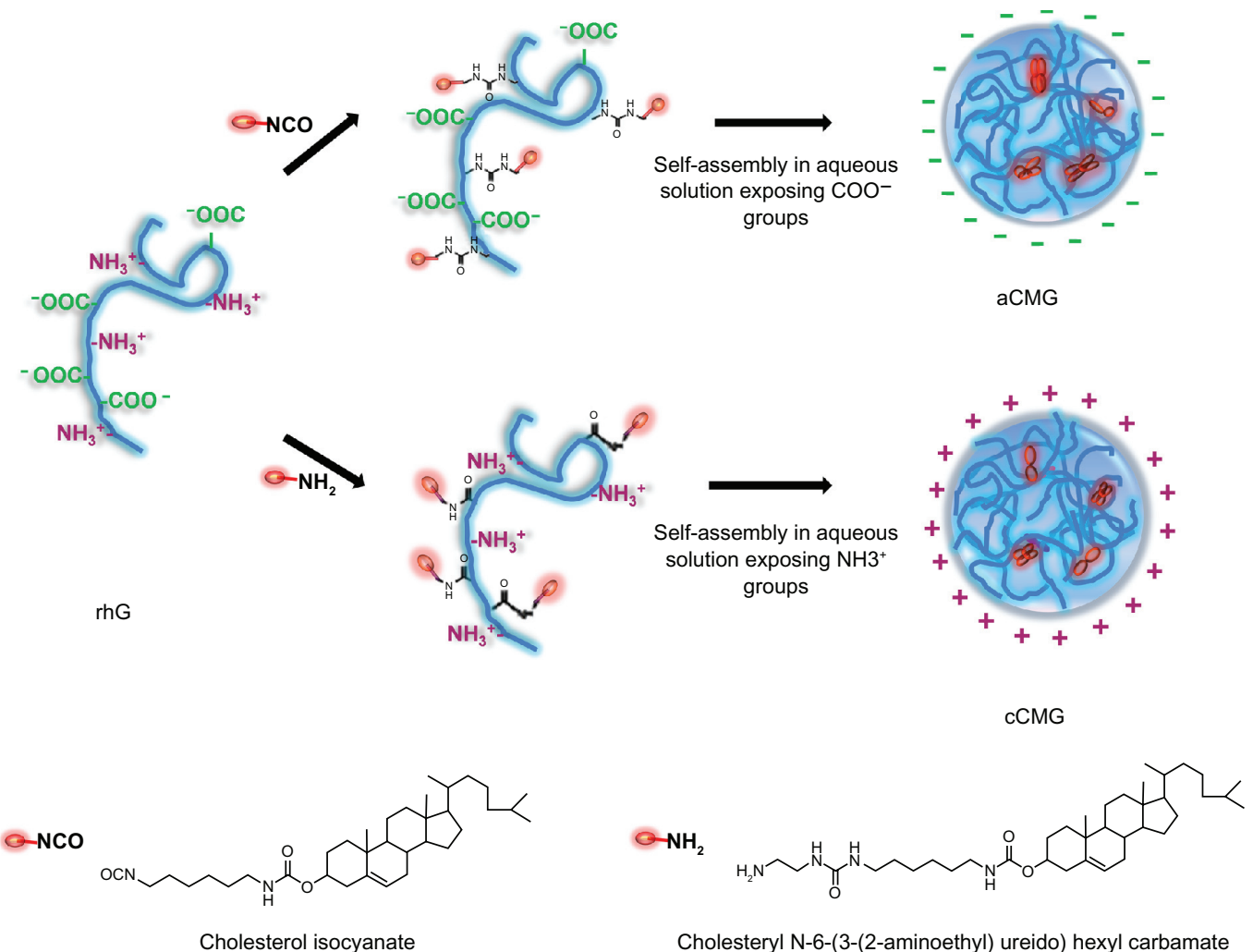

Figure 2 Illustration of the synthesis of aCMG and CCMG from rhG and their self-assembly in aqueous solution.

Notes: For aCMG, cholesterol isocyanate is conjugated with the amino groups of the lysine moieties of rhG and dispersed in aqueous solution to expose the free COOgroups, thereby attaining an overall negative charge. On the other hand, during the synthesis of cCMG, amino-modified cholesterol reacts with the $\mathrm{COOH}$ groups of aspartate and glutamate present in rhG. These disperse on hydration and expose free $\mathrm{NH}_{3}{ }^{+}$groups to attain an overall positive charge.

Abbreviations: aCMG, anionic cholesterol-modified gelatin; cCMG, cationic cholesterol-modified gelatin; rhG, recombinant human gelatin.
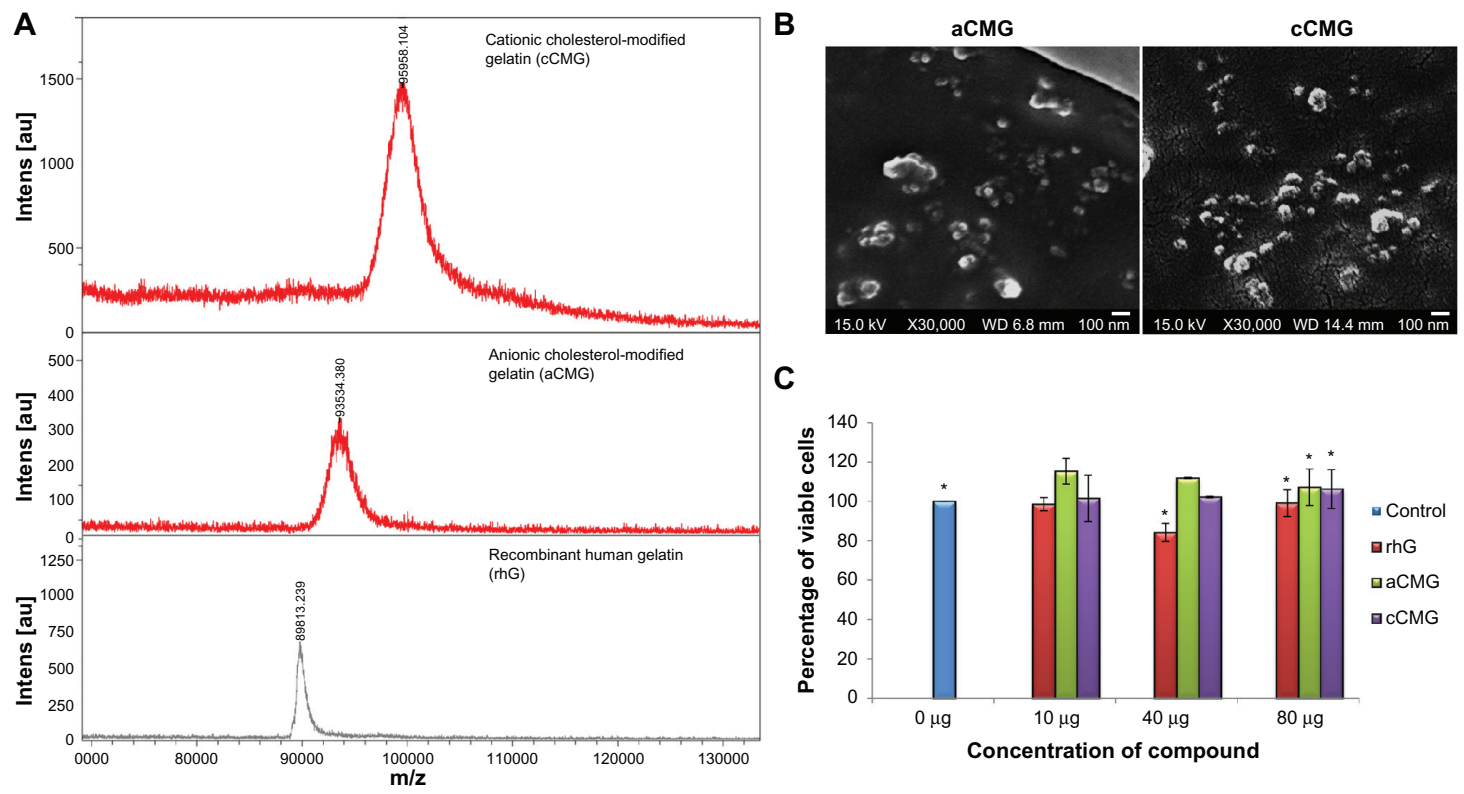

Figure 3 (A) MALDI-TOF mass spectra of the polymeric micelles, aCMG and cCMG. The masses of the cholesterol-modified gelatins were compared with that of native rhG to confirm the synthesis. (B) SEM images of aCMG and cCMG micelles. Samples were at a concentration of I mg/mL. Scale bar $=100 \mathrm{~nm}$. The hydrodynamic size of the polymeric micelles estimated by DLS was larger than that observed by SEM. This discrepancy in size can be attributed to shrinkage of the particles during air-drying prior to SEM analysis. (C) Cytotoxicity of the polymeric micelles aCMG and cCMG versus native rhG (control) in DC 2.4 cells at concentrations of I0, 40 , and $80 \mu \mathrm{g}$.

Notes: The cells were incubated with the polymers for 24 hours. Data are presented as the mean \pm SD $(n=3) ; * P>0.05$.

Abbreviations: aCMG, anionic cholesterol-modified gelatin; cCMG, cationic cholesterol-modified gelatin; DCs, dendritic cells; MALDI-TOF, matrix-assisted laser desorption/ ionization time-of-flight mass spectrometry; rhG, recombinant human gelatin; SD, standard deviation; SEM, scanning electron microscopy. 


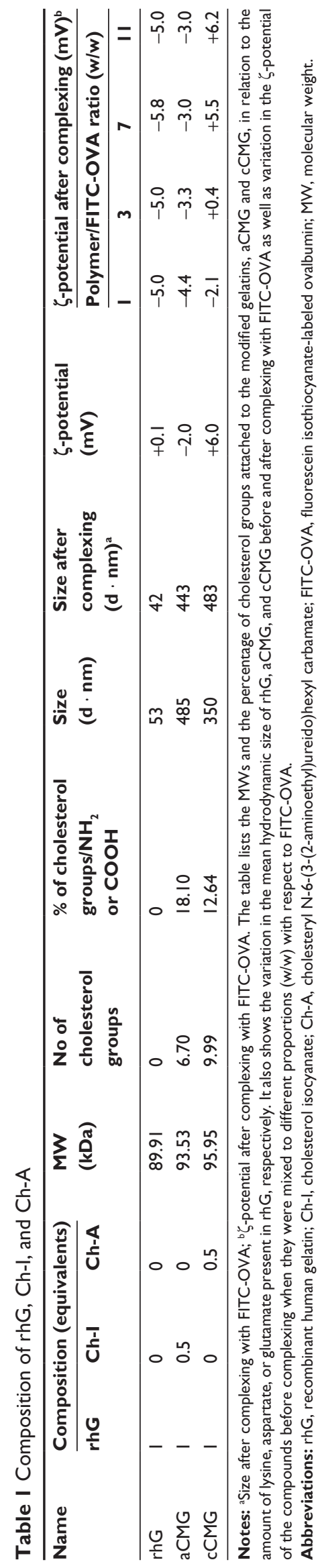

used in biological fluids, ${ }^{20,21}$ which makes them amphiphilic in nature, and thus preventing gelatin from being dissolved rapidly in an aqueous environment.

SEM images further elucidated the formation of micelles. Figure 3B shows the SEM images of anionic and cationic polymeric micelles. The hydrodynamic size of the polymeric micelles by DLS was larger than that observed by SEM. This discrepancy in size can be attributed to the shrinking of the particles during air-drying prior to SEM analysis.

It was also found that aCMG as well as $\mathrm{CCMG}$ showed no cytotoxicity at a maximum concentration of $\sim 1 \mu \mathrm{M}(80 \mu \mathrm{g})$ (Figure 3C).

\section{Complex formation of the polymeric micelles with ovalbumin}

FITC-OVA was used to form a complex with the polymeric micelles. Table 1 shows the changes in $\zeta$-potential. In the case of cCMG, at a polymer-to-protein weight ratio (w/w) of 1.0, the polymeric micelle-protein complex was negatively charged. On increasing the concentration of $\mathrm{cCMG}$ with respect to protein, the $\zeta$-potential became more positively charged. Here, the anionic protein interacted with cCMG through electrostatic interactions, which are considered to be the main driving force for the binding of the protein. The positively charged amino groups in cCMG appeared to be very effective in the formation of a complex with FITCOVA. On the other hand, the $\zeta$-potential of aCMG remained constant even in the presence of FITC-OVA. Similarly, the $\zeta$-potential of rhG remained constant at all proportions with FITC-OVA. The formation of complexes was elucidated further by measuring size distributions using DLS (Table 1). The mean hydrodynamic size of cCMG complexed with FITC-OVA increased significantly from 350 to $483 \mathrm{~nm}$ whereas the size of aCMG as well as rhG remained the same, which can be attributed to their failure in forming a complex with the protein. Strong complex formation of cCMG was also demonstrated by native polyacrylamide gel electrophoresis analysis (Figure S2).

\section{Uptake of antigenic protein by immature dendritic cells}

Following treatment of DC 2.4 cells with cCMG, flow cytometry analysis revealed a large population of cells with intense fluorescence whereas few cells were positive for fluorescence among the free FITC-OVA, rhG- and aCMGtreated cells (Figure 4A). Cells incubated with cCMG at $4^{\circ} \mathrm{C}$ revealed a much lower uptake than at $37^{\circ} \mathrm{C}$ (Figure S3), as is known for polymer-based nanoparticles. ${ }^{22}$ This result 
A

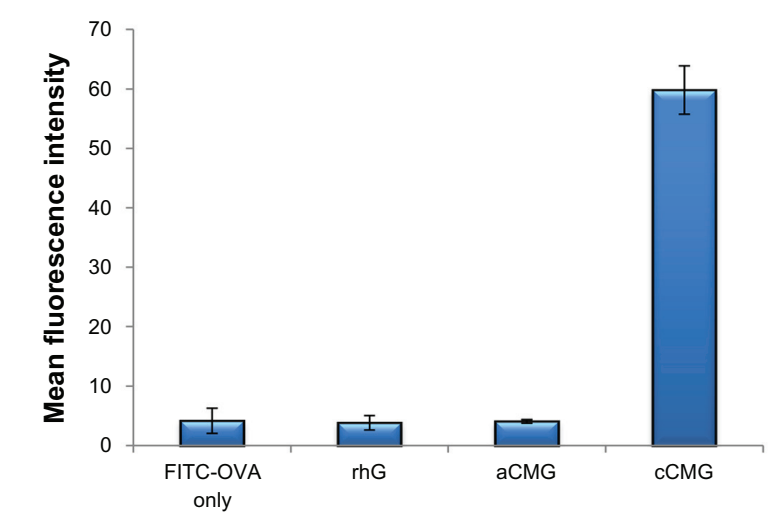

B

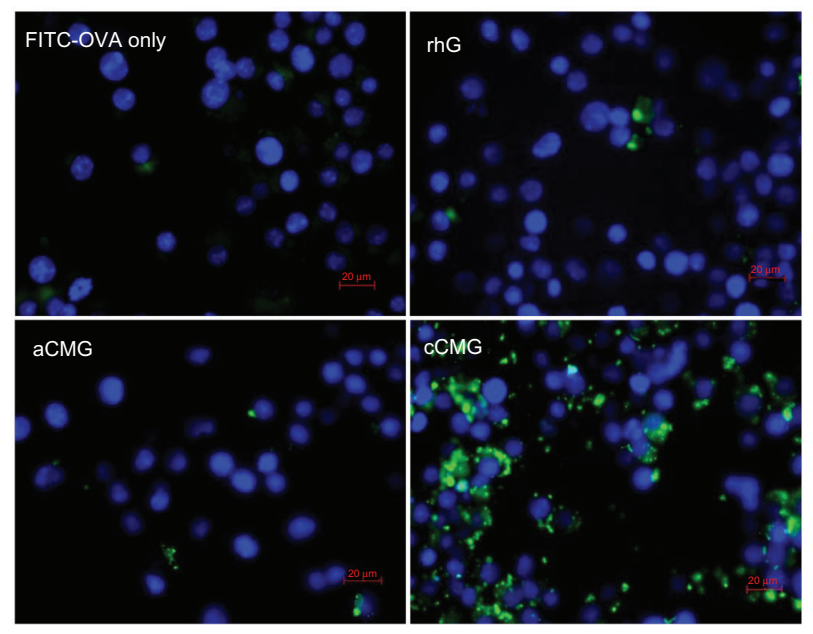

Figure 4 (A) FACS analysis of DC 2.4 cells incubated with rhG, aCMG and cCMG complexed with FITC-OVA for I hour at $37^{\circ} \mathrm{C}$. Results are expressed as mean fluorescence intensity of the specific uptake of protein. This was assessed by subtracting the mean fluorescence intensity of cells incubated at $4^{\circ} \mathrm{C}$ from the value obtained at $37^{\circ} \mathrm{C}$. (B) Fluorescent images show the cell uptake of FITC-OVA (green) in dendritic (DC 2.4) cells treated with FITC-OVA alone, or with rhG, aCMG, or $\mathrm{CCMG}$ at $37^{\circ} \mathrm{C}$ for 4 hours in RPMI- 1640 medium supplemented with $10 \%$ fetal bovine serum.

Notes: After incubation, the cells were washed with phosphate-buffered saline (PBS) and fixed in $4 \%$ paraformaldehyde. Cells were stained with DAPI for nuclear DNA (blue). Scale bars $=20 \mu \mathrm{m}$.

Abbreviations: aCMG, anionic cholesterol-modified gelatin; cCMG, cationic cholesterol-modified gelatin; DCs, dendritic cells; FACS, fluorescence-activated cell sorting; FITC-OVA, fluorescein isothiocyanate-labeled ovalbumin; rhG, recombinant human gelatin.

demonstrated that the cellular uptake was caused by an active process of internalization and not by a passive one. Figure $3 \mathrm{~B}$ also shows a marked increase in the uptake of the protein by $\mathrm{cCMG}$, caused by interactions between the cationic charges on the surface of the polymeric micelles and the anionic domains present on the cell surface. The appearance of strong fluorescence at certain points after 2 hours and its distribution throughout the cytosol after 24 hours was observed by fluorescence microscopy (Figure S4).

\section{Cytoplasmic delivery of antigenic protein by polymeric micelles}

To investigate whether the proteins had escaped lysosomal degradation, the DC 2.4 cells were stained with LysoTracker ${ }^{\mathrm{TM}}$ Red, which accumulates in late endosomes and lysosomes. In the case of DC 2.4 cells treated with rhG and aCMG (Figure 5A), after 24 hours the protein was detected along with the lysosomes that were obvious in the colocalization signals of FITC-OVA (green) and LysoTrackerTM (red) that together appeared yellow. In contrast, DC 2.4 cells treated with cCMG showed strong green as well as red fluorescence. Thus, the protein delivered by cCMG was not trapped in lysosomes. Except for some locations (partial colocalizations indicated by white circles in Figure 5A), there was no colocalization of signals, confirming that FITC-OVA and lysosomes were present at different locations. This showed that the proteins had been released efficiently into the cell cytosol.

OVA-DQ ${ }^{\mathrm{TM}}$ was employed to visualize the processing of antigen into peptides. This is a self-quenching ovalbumin conjugate that emits bright green fluorescence upon enzymatic degradation into single peptides. Figure 5B shows that there was bright green fluorescence after 5 hours of incubation with cCMG. This became more diffuse and spread throughout the cell after 24 hours. This result indicates the efficient processing of OVA into peptides by DC 2.4 cells.

\section{Uptake mechanism}

To investigate the mechanism of uptake of cCMG by the DC 2.4 cells, we used four chemical inhibitors that block endocytosis pathways. These were: chlorpromazine, a potent inhibitor of clathrin-mediated endocytosis; ${ }^{23}$ nystatin and genistein, which both block caveolin-mediated endocytosis, ${ }^{24}$ and cytochalasin $\mathrm{D}$, an actin inhibitor that blocks the macropinocytosis pathway. ${ }^{25}$ Of these inhibitors, chlorpromazine and genistein reduced the uptake to about $67 \%$ and $40 \%$, respectively, when compared with the control untreated cells and showing $98 \%$ fluorescent positive cells (Figure 6A). The result from chlorpromazine inhibition demonstrated that cCMG was internalized into the DCs via a clathrin-mediated pathway and ultimately entered the lysosomal compartments (partial colocalization; Figure 5A) ${ }^{26}$ To enter efficiently via this pathway, it is important for the compound to possess properties that can escape lysosomes efficiently, as in the case of N-[1-(2,3-dioleyloxy) propyl]-N,N,N-trimethylammonium methyl-sulfate (DOTAP) lipids. ${ }^{26}$ In addition to this pathway, the result from genistein inhibition indicated the presence of a caveolin-mediated 


\section{A} Lysotracker + DAPI
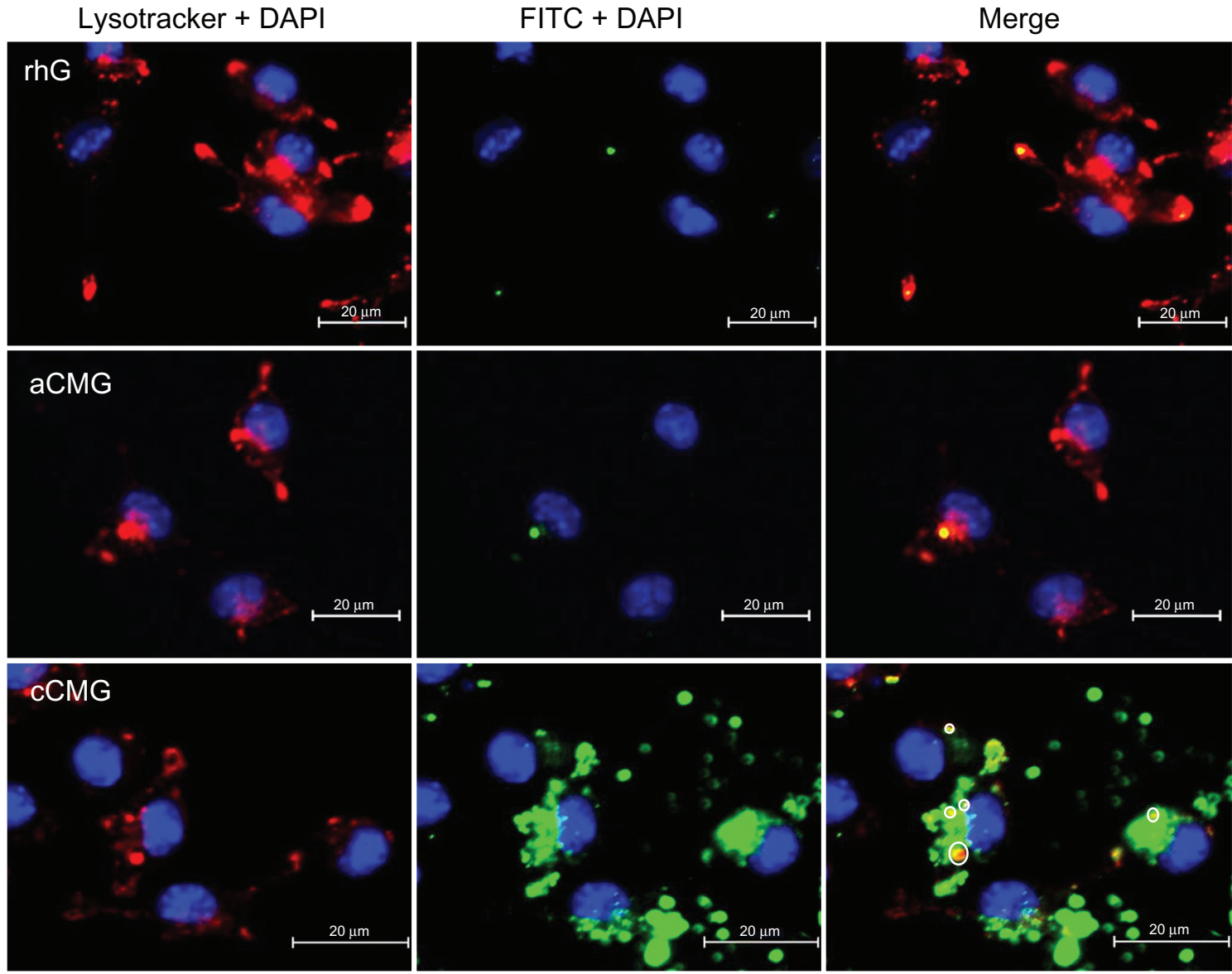

B
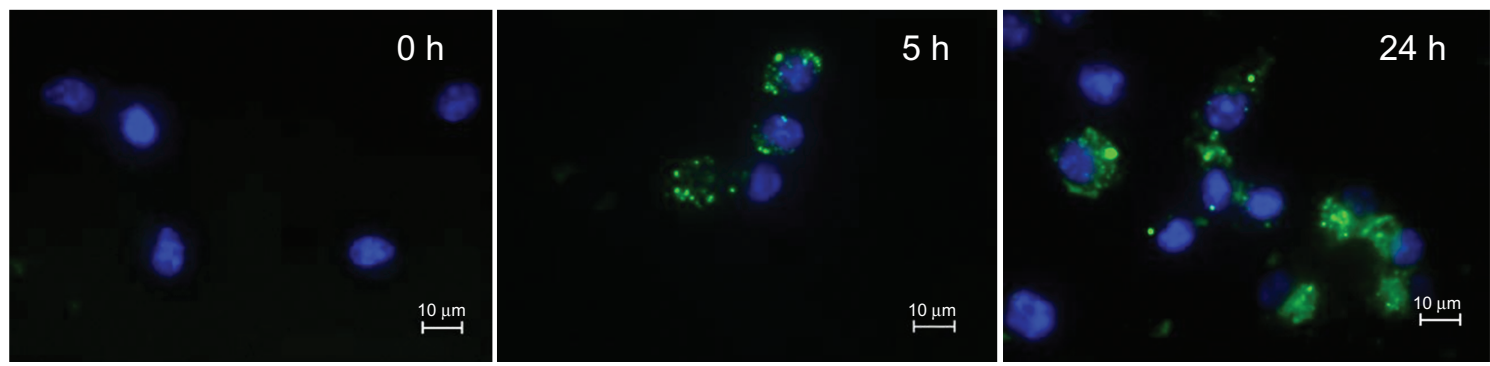

Figure 5 (A) Fluorescent images of DC 2.4 cells treated with rhG, aCMG, or cCMG complexed with FITC-OVA (green) in complete medium at $37^{\circ} \mathrm{C}$ for 5 hours. After 5 hours, the medium was replaced with fresh complete medium and incubated for an additional 19 hours. LysoTracker ${ }^{\mathrm{TM}}$ Red was added 20 minutes before fixing the cells with $4 \%$ paraformaldehyde to visualize acidic cell compartments: late endosomes and lysosomes (red). Cells were stained with DAPI for nuclear DNA (blue). Scale bars $=20 \mu \mathrm{m}$. (B) Processing of OVA was analyzed using OVA-DQ ${ }^{\mathrm{TM}}$.

Notes: DCs were incubated with OVA-DQ ${ }^{\mathrm{TM}}$ complexed with CCMG for 0,5 , and 24 hours and fixed. The figures are an overlay of green fluorescence (OVA-DQ $\left.{ }^{\mathrm{TM}}\right)$ and blue fluorescence (DAPI). Scale bars $=10 \mu \mathrm{m}$.

Abbreviations: aCMG, anionic cholesterol-modified gelatin; cCMG, cationic cholesterol-modified gelatin; rhG, recombinant human gelatin; DC, dendritic cell; FITC-OVA, fluorescein isothiocyanate labeled-ovalbumin; DAPI, 4',6-diamidino-2-phenylindole.

pathway, which is known to avoid the lysosomes. ${ }^{27}$ This was considered to be the major uptake mechanism (strong green fluorescence, Figure 5A). Interestingly, treatment with nystatin failed to inhibit the endocytosis of cCMG. It has been reported that the uptake of polyethyleneimine, a well-studied cationic polymer that utilizes the caveolin pathway for endocytosis, is inhibited by nystatin ${ }^{28}$ as well as by genistein. ${ }^{26}$ Nystatin is a sterol-binding drug. ${ }^{24}$ Hence, when cells are pretreated with it there is a depletion of cholesterol. It is known that treatment with cholesterol-depleting drugs cannot block Kirsten Ras (KRas)-mediated activation, ${ }^{29}$ which results in an efficient uptake of cCMG even after treatment. Considering that genistein inhibits the protein tyrosine kinases, ${ }^{24}$ we conclude that the uptake of cCMG was mediated by a caveolin-mediated 

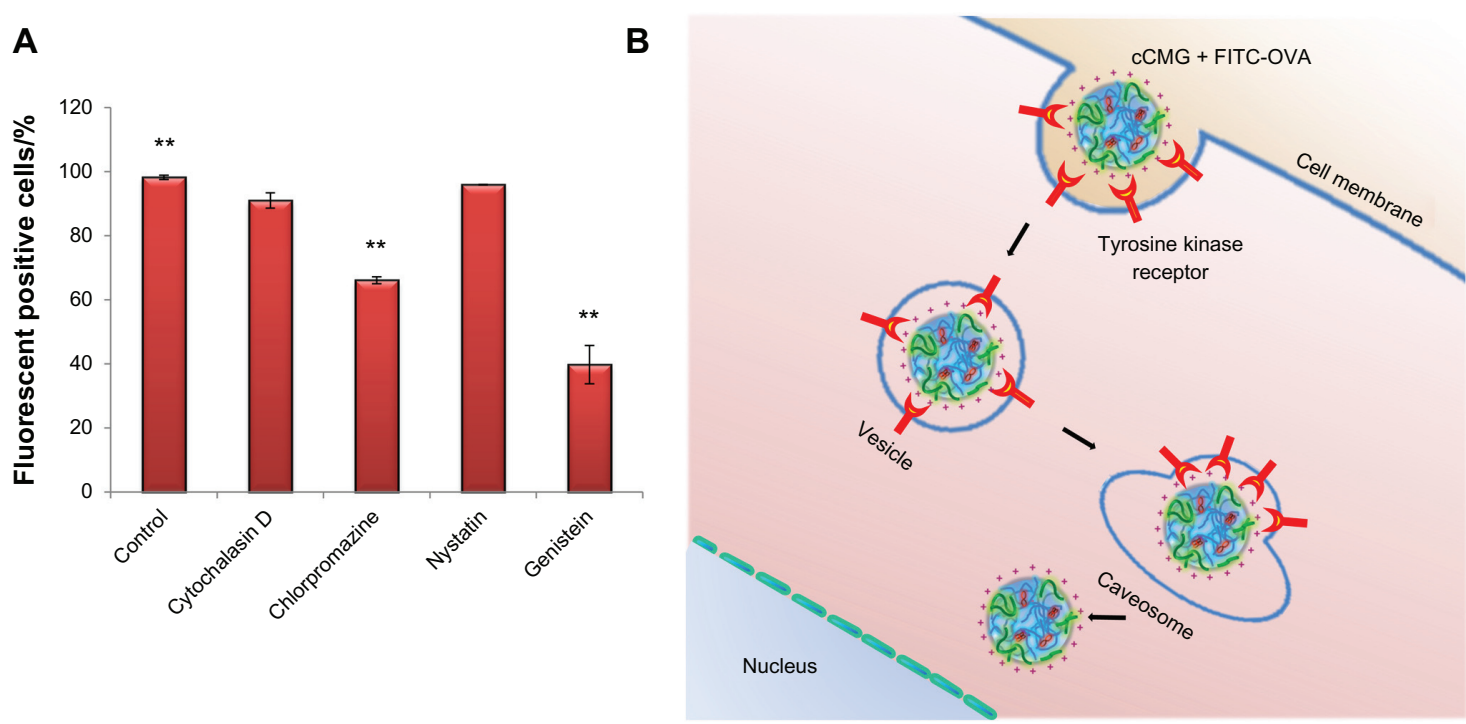

Figure 6 (A) Inhibition study by flow cytometry using various inhibitors of endocytosis. Results are expressed as the percentage of fluorescent positive cells. Control cells were treated with cCMG complexed with FITC-OVA only; **P $<0.0$ I. (B) OVA-specific antibody titers after an intraperitoneal injection of free OVA and cCMG complexed with OVA in mice on day 7 after the first vaccination and day 21 after the first booster dose, by endpoint ELISA.

Notes: The results are expressed as the mean \pm SD of three independent experiments. Significant differences between the groups: $* * P<0.01$.

Abbreviations: cCMG, cationic cholesterol-modified gelatin; FITC-OVA, fluorescein isothiocyanate-labeled ovalbumin; OVA, ovalbumin; rhG, recombinant human gelatin; SD, standard deviation.

pathway through specific interactions with tyrosine kinase receptors (Figure 6B).

\section{Antigen-specific antibody production in vivo}

The induction of humoral immune responses by cCMGOVA was investigated using mice. Serum samples were collected once a week from C57BL/6 mice immunized intraperitoneally with OVA or cCMG-OVA and OVAspecific antibody titers were measured using an endpoint
ELISA. A high antibody titer in mice immunized with cCMG-OVA was observed as early as 7 days after the first immunization. On day 21, the OVA-specific antibody titer in these mice was $>2580$-fold higher than that in mice immunized with free OVA (Figure 7). Antigen doses as low as $1 \mu \mathrm{g}$ were sufficient to induce immunity (data not shown). These results are consistent with our in vitro data. They illustrate the stability of the micelles, which is another important factor to consider when delivering proteins via nanoparticles in vivo. If there had been no significant
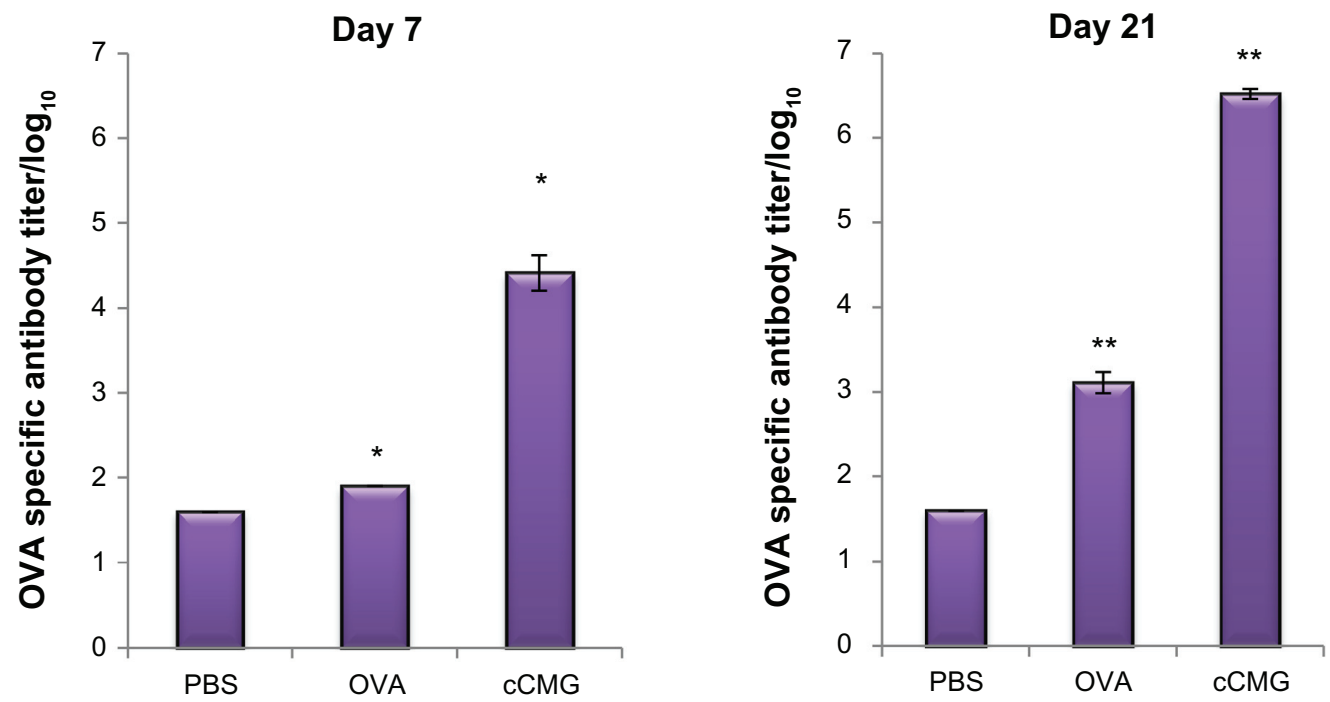

Figure 7 Specific antibody titers against OVA in murine blood were determined by ELISA after injection of PBS, OVA, or OVA-cCMG.

Notes: The results are expressed as the mean $\pm S D$ of three independent experiments. Significant differences between the groups: $* P<0.05$; $* * P<0.01$.

Abbreviations: cCMG, cationic cholesterol-modified gelatin; OVA, ovalbumin; PBS, phosphate-buffered saline. 
increase in the serum IgG levels in mice after immunization with cCMG, it could have been attributed to the instability of the polymeric micelles upon their interaction with the body's serum proteins and other enzymes, ultimately leading to their degradation. This was observed only in the case of free OVA, where there was only a minimal production of serum antibodies against OVA and not in the case of cCMG.

The successful delivery of cCMG as well as the efficient production of antibodies in vivo derived from the combined effect of size, a strong complex formation with protein, efficient release of the protein into the cytoplasm by caveolin-mediated endocytosis, and the processing of protein for antigen presentation by the DCs. Antigen presentation is generally enhanced by antigen carriers that lie within the size range of $0.1-10 \mu \mathrm{m}$, which apparently increases cross-presentation of the antigen to T-cells. ${ }^{30}$ Understanding the subcellular localization of an antigen by polymeric micelles is crucial for their application in drug delivery. Escape of the antigen from lysosomes is considered an important step in the success of vaccine therapy. An increase in the cytosolic delivery of the protein antigen facilitates cross presentation of the antigen loaded onto MHC-I molecules to activate T-cells. This is achieved when the antigen is processed by proteases present in the cytosolic-based proteasomes. ${ }^{31}$ We believe this to hold true in the case of cCMG.

\section{Conclusion}

In conclusion, we have shown for the first time the successful synthesis of cationic cholesterol-modified gelatin and have evaluated its efficiency in inducing humoral immunity in mice. We used a simple method of loading protein into the polymeric micelles via complex formation through electrostatic interaction. The ability of cCMG to deliver an antigen with high efficiency, stability, and negligible cytotoxicity should open new doors in the field of drug delivery, particularly for proteins. This should bring us a step closer to translating our work from academic research to practical applications.

\section{Acknowledgment}

This work was supported by a grant from the Program for the Promotion of Basic and Applied Research for Innovations in Bio-oriented Industry.

\section{Disclosure}

The authors report no conflicts of interest in this work.

\section{References}

1. Banchereau J, Steinman RM. Dendritic cells and the control of immunity. Nature. 1998;392(6673):245-252.

2. Chen J, Li Z, Huang H, et al. Improved antigen cross-presentation by polyethyleneimine-based nanoparticles. Int J Nanomedicine. 2011;6: $77-84$.

3. Lee $\mathrm{Y}$, Ishii T, Cabral H, et al. Charge-conversional polyionic complex micelles - efficient nanocarriers for protein delivery into cytoplasm. Angew Chem Int Ed Engl. 2009;48(29):5309-5312.

4. Yuba E, Kojima C, Harada A, Tana, Watarai S, Kono K. pH-Sensitive fusogenic polymer-modified liposomes as a carrier of antigenic proteins for activation of cellular immunity. Biomaterials. 2010;31(5): 943-951.

5. Quintilio W, Takata CS, Sant'Anna OA, da Costa MH, Raw I. Evaluation of a diphtheria and tetanus PLGA microencapsulated vaccine formulation without stabilizers. Curr Drug Deliv. 2009;6(3): 297-304.

6. Akiyoshi K, Deguchi S, Moriguchi N, Yamaguchi S, Sunamoto J. Self-aggregates of hydrophobized polysaccharides in water. Formation and characteristics of nanoparticles. Macromolecules. 1993;26(12): 3062-3068.

7. MaY, Zheng Y, Liu K, et al. Nanoparticles of poly(lactide-co-glycolide)d-a-tocopheryl polyethylene glycol 1000 succinate random copolymer for cancer treatment. Nanoscale Res Lett. 2010;5(7):1161-1169.

8. Park K, Kim K, Kwon IC, et al. Preparation and characterization of self-assembled nanoparticles of heparin-deoxycholic acid conjugates. Langmuir. December 21, 2004;20(26):11726-11731.

9. Coester C, Nayyar P, Samuel J. In vitro uptake of gelatin nanoparticles by murine dendritic cells and their intracellular localisation. Eur $J$ Pharm Biopharm. 2006;62(3):306-314.

10. GuptaAK, Gupta M, Yarwood SJ, Curtis AS. Effect of cellular uptake of gelatin nanoparticles on adhesion, morphology and cytoskeleton organisation of human fibroblasts. J Control Release. 2004;95(2): 197-207.

11. Ofokansi K, Winter G, Fricker G, Coester C. Matrix-loaded biodegradable gelatin nanoparticles as new approach to improve drug loading and delivery. Eur J Pharm Biopharm. 2010;76(1):1-9.

12. Wareechuensook M, Tabata Y, Kanokpanont S. Characteristics of cholesterol-grafted gelatin micelles. Adv Mater Res. 2010;93-94: 595-598.

13. Han B, Jaurequi J, Tang BW, Nimni ME. Proanthocyanidin: a natural crosslinking reagent for stabilizing collagen matrices. J Biomed Mater Res A. 2003;65A(1):118-124.

14. Sakaguchi M, Inouye S. Systemic allergic reactions to gelatin included in vaccines as a stabilizer. Jpn J Infect Dis. 2000;53(5):189-195.

15. Asher DM. The transmissible spongiform encephalopathy agents: concerns and responses of United States regulatory agencies in maintaining the safety of biologics. Dev Biol Stand. 1999;100: 103-118.

16. Olsen D, Jiang J, Chang R, et al. Expression and characterization of a low molecular weight recombinant human gelatin: development of a substitute for animal-derived gelatin with superior features. Protein Expr Purif. 2005;40(2):346-357.

17. Won Y-W, Kim Y-H. Recombinant human gelatin nanoparticles as a protein drug carrier. J Control Release. 2008;127(2):154-161.

18. Adachi T, Wang X, Murata T, et al. Production of a non-triple helical collagen $\alpha$ chain in transgenic silkworms and its evaluation as a gelatin substitute for cell culture. Biotechnol Bioeng. 2010;106(6):860-870.

19. Sun H, Guo B, Li X, et al. Shell-sheddable micelles based on dextranSS-poly(epsilon-caprolactone) diblock copolymer for efficient intracellular release of doxorubicin. Biomacromolecules. 2010;11(4): 848-854.

20. Guo XD, Tandiono F, Wiradharma N, et al. Cationic micelles selfassembled from cholesterol-conjugated oligopeptides as an efficient gene delivery vector. Biomaterials. 2008;29(36):4838-4846.

21. Oba M, Miyata K, Osada K, et al. Polyplex micelles prepared from omega-cholesteryl PEG-polycation block copolymers for systemic gene delivery. Biomaterials. 2011;32(2):652-663. 
22. Yan M, Du J, Gu Z, et al. A novel intracellular protein delivery platform based on single-protein nanocapsules. Nat Nanotechnol. 2010;5(1): 48-53.

23. Wang LH, Rothberg KG, Anderson RG. Mis-assembly of clathrin lattices on endosomes reveals a regulatory switch for coated pit formation. J Cell Biol. 1993;123(5):1107-1117.

24. Van Hamme E, Dewerchin HL, Cornelissen E, Verhasselt B, Nauwynck HJ. Clathrin- and caveolae-independent entry of feline infectious peritonitis virus in monocytes depends on dynamin. J Gen Virol. 2008;89(9): 2147-2156.

25. Gold S, Monaghan P, Mertens P, Jackson T. A Clathrin independent macropinocytosis-like entry mechanism used by bluetongue virus-1 during infection of BHK cells. PLoS One. 2010;5(6):e11360.

26. Rejman J, Bragonzi A, Conese M. Role of clathrin- and caveolaemediated endocytosis in gene transfer mediated by lipo- and polyplexes. Mol Ther. 2005;12(3):468-474.
27. Shin J-S, Abraham SN. Caveolae as portals of entry for microbes. Microbes Infect. 2001;3(9):755-761.

28. Grosse S, Aron Y, Thévenot G, François D, Monsigny M, Fajac I. Potocytosis and cellular exit of complexes as cellular pathways for gene delivery by polycations. J Gene Med. 2005;7(10):1275-1286.

29. Hancock JF. Ras proteins: different signals from different locations. Nat Rev Mol Cell Biol. 2003;4(5):373-385.

30. De Koker S, De Geest BG, Singh SK, et al. Polyelectrolyte microcapsules as antigen delivery vehicles to dendritic cells: uptake, processing, and cross-presentation of encapsulated antigens. Angew Chem Int Ed Engl. 2009;48(45):8485-8489.

31. Tacken PJ, de Vries IJ, Torensma R, Figdor CG. Dendritic-cell immunotherapy: from ex vivo loading to in vivo targeting. Nat Rev Immunol. 2007;10:790-802. 


\section{Supplementary figures}
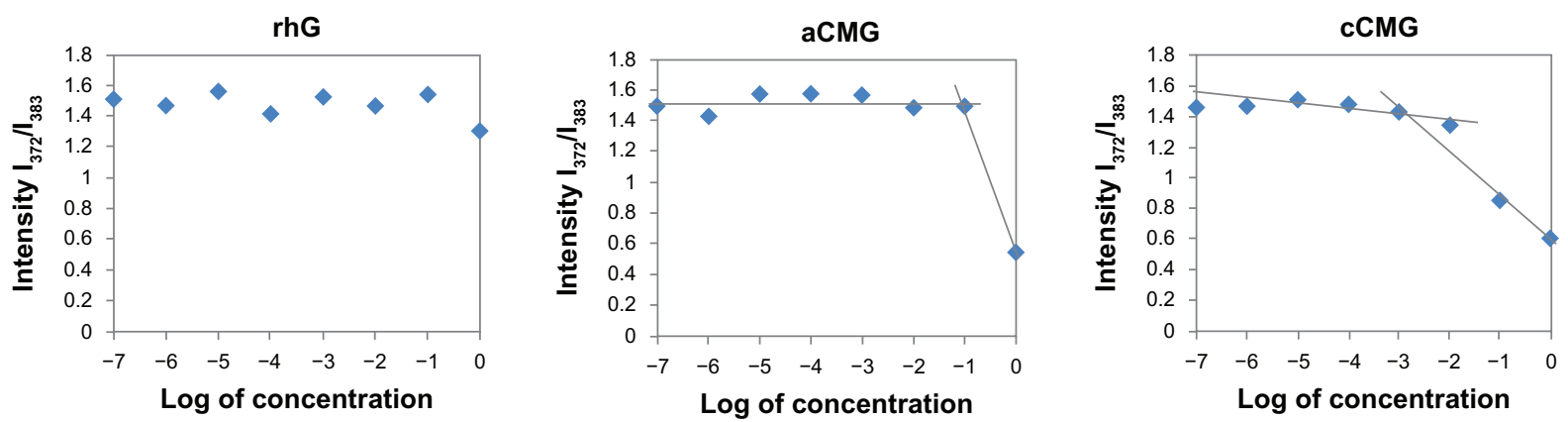

Figure SI Critical micelle concentration $(\mathrm{CMC})$ values of aCMG $\left(1.7 \times 10^{-2} \mathrm{mg} / \mathrm{mL}\right)$ and cCMG $\left(2.0 \times 10^{-3} \mathrm{mg} / \mathrm{mL}\right)$ analyzed by fluorescence spectrometry with the fluorescence intensity ratio $I_{1} / I_{3}$ of pyrene as a function of the concentration of modified gelatin.

Note: The native rhG does not form micelles and so does not have any CMC.

Abbreviations: aCMG, anionic cholesterol-modified gelatin; cCMG, cationic cholesterol-modified gelatin.

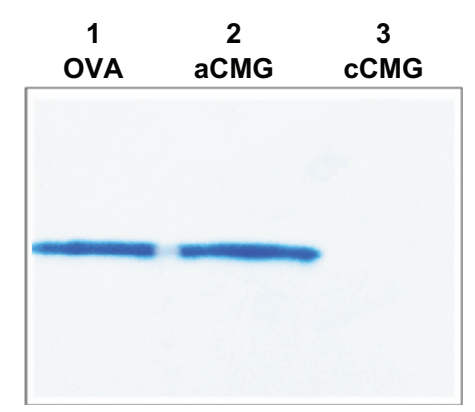

Figure S2 Confirmation of complex formation with OVA by aCMG or CCMG, as determined by native polyacrylamide gel electrophoresis analysis.

Notes: The gel was stained with Coomassie Brilliant Blue (stacking gel $-3 \%$ and separating gel -12.5\%). Lane I, OVA; Lane 2, aCMG with OVA; Lane 3, cCMG with OVA.

Abbreviations: aCMG, anionic cholesterol-modified gelatin; cCMG, cationic cholesterol-modified gelatin; OVA, ovalbumin.

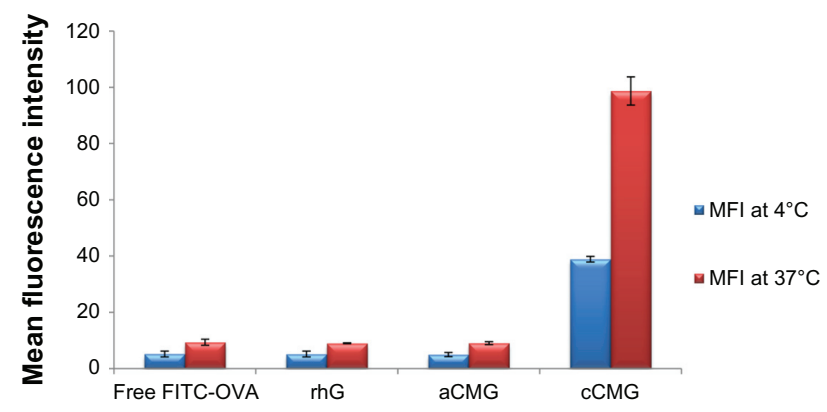

Figure S3 FACS analysis of the cellular uptake of free FITC-OVA, rhG, aCMG, and cCMG at 4 and $37^{\circ} \mathrm{C}$.

Abbreviations: aCMG, anionic cholesterol-modified gelatin; cCMG, cationic cholesterol-modified gelatin; FACS, fluorescence-activated cell-sorting; FITC-OVA, fluorescein isothiocyanate-labeled ovalbumin; MFI; mean fluorescence intensity; rhG, recombinant human gelatin.
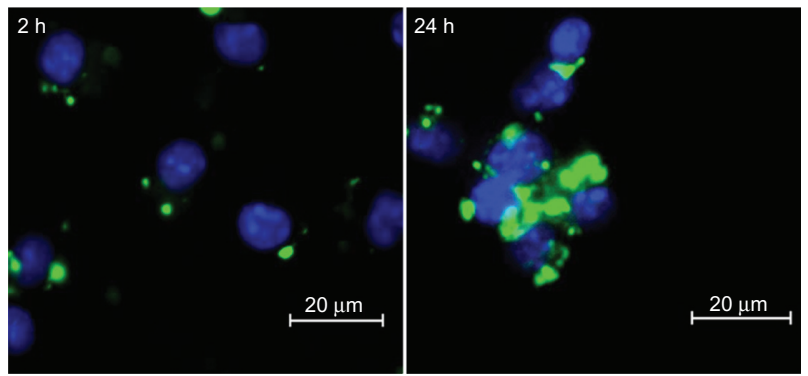

Figure S4 Fluorescence microscopy results of a time-course study on the uptake of cCMG by DC 2.4 cells after 2 and 24 hours.

Note: Intracellular FITC-OVA (green) was observed.

Abbreviations: cCMG, cationic cholesterol-modified gelatin; DCs, dendritic cells; FITC-OVA, fluorescein isothiocyanate-labeled ovalbumin. 


\section{Publish your work in this journal}

The International Journal of Nanomedicine is an international, peerreviewed journal focusing on the application of nanotechnology in diagnostics, therapeutics, and drug delivery systems throughout the biomedical field. This journal is indexed on PubMed Central, MedLine, CAS, SciSearch $\AA$, Current Contents ${ }^{\circledR} /$ Clinical Medicine,
Journal Citation Reports/Science Edition, EMBase, Scopus and the Elsevier Bibliographic databases. The manuscript management system is completely online and includes a very quick and fair peer-review system, which is all easy to use. Visit http://www.dovepress.com/ testimonials.php to read real quotes from published authors.

Submit your manuscript here: http://www.dovepress.com/international-journal-of-nanomedicine-journal 